\title{
Immunological changes after dehydration resulting from physical effort in a hot environment
}

\author{
J. Romeo ${ }^{1}$, D. Jimenez-Pavón ${ }^{2,3}$, M. Cervantes-Borunda ${ }^{4}$, J. Wärnberg ${ }^{1}$, L. E. Díaz ${ }^{1}$ and A. Marcos ${ }^{1}$ \\ ${ }^{1}$ Immunonutrition Research Group, Department of Metabolism and Nutrition, Consejo Superior de Investigaciones \\ Cientificas, Madrid, Spain, ${ }^{2}$ Research Group EFFECTS 262, Department of Medical Physiology, School of Medicine, \\ University of Granada, Granada, Spain, ${ }^{3}$ Facultad de Ciencias de la Actividad Física y del Deporte, Universidad \\ Politécnica de Madrid, Madrid, Spain and ${ }^{4}$ Facultad de Educación Física y Ciencias del Deporte, Universidad \\ de Chihuahua, México
}

Intensive exercise is well known to affect the immune function, leading to higher risk of infections and inflammatory processes in sportsmen ${ }^{(1-3)}$. Several factors are involved in the immune modulation, such as the intensity and duration of the physical activity as well as inter-individual variations ${ }^{(4,5)}$. Thus, the aim of the present study was to confirm the effects of intensive physical effort in a relatively short time period and high environmental temperature on variables of immune function and inflammatory markers. A total of twenty-two young male adults (age 21.2 ( $\mathrm{SD} 1.7$ ) years; $\mathrm{V}_{\mathrm{O} 2 \mathrm{max}} 55.4$ (SD 3.6) $\mathrm{ml} / \mathrm{kg}$ per min) volunteered to participate in an exercise session of $60 \mathrm{~min}$ on a treadmill ergometer at moderate speed (60\% maximum aerobic speed) in hot environmental conditions $\left(35^{\circ} \mathrm{C}\right.$ and humidity $\left.65 \%\right)$. Total leucocyte and lymphocyte counts, absolute values of T-lymphocyte CD8+, CD4+, CD3+, natural killer and CD19+ subsets and the capacity of cytokine production (IL-2, IL-4, IL-5, IL-10, interferon- $\gamma$ and TNFo) were evaluated before and after exercise without rehydration. Several inflammation-related proteins (caeruloplasmin, C-reactive protein, C3 and C4) were also measured. The results show that absolute numbers of leucocytes and neutrophils increased while eosinophils decreased after the intensive exercise. In addition, caeruloplasmin, C3 and C4 levels also increased after exercise. In contrast, no changes in T-lymphocyte subsets or cytokine production were observed.

\begin{tabular}{|c|c|c|c|c|}
\hline & \multicolumn{2}{|c|}{ Before exercise } & \multicolumn{2}{|c|}{ After exercise } \\
\hline & Mean & SD & Mean & SD \\
\hline Leucocytes $\left(\times 10^{9} / 1\right)$ & 5.73 & 1.48 & $8.84^{*}$ & 2.39 \\
\hline Neutrophils $\left(\times 10^{9} / 1\right)$ & 3.56 & 1.10 & $6.83^{*}$ & 2.17 \\
\hline Lymphocytes $\left(\times 10^{9} / 1\right)$ & 1.68 & 0.44 & 1.59 & 0.30 \\
\hline Eosinophils $\left(\times 10^{9} / 1\right)$ & 0.17 & 0.13 & $0.08^{*}$ & 0.05 \\
\hline Caeruloplasmin $(\mathrm{mg} / \mathrm{l})$ & 325.8 & 49.6 & $342.8^{*}$ & 56.3 \\
\hline C3 (g/l) & 0.99 & 0.14 & $1.04 *$ & 0.13 \\
\hline C4 (g/l) & 0.23 & 0.07 & $0.25^{*}$ & 0.07 \\
\hline
\end{tabular}

Since prolonged bouts of intensive exercise cause a temporary reduction in various aspects of immune function that usually lasts $3-24 \mathrm{~h}$ after exercise, the results confirm those from previous studies and suggest that 60 min exercise in a hot environment is enough to cause an immune system adaptation to these conditions leading to an increase in some immune cells and promoting inflammatory processes. Interestingly, these changes in immune cells have not altered the T-lymphocyte subsets and the capacity for cytokine production; therefore, immune cell function seems to be preserved in relatively-short-term acute exercise. Further research is necessary to determine to what extent habitual intensive exercise under high environmental temperature can impair the immune system.

1. Gleeson M (2007) J Appl Physiol 15 (Epublication ahead of print version).

2. Nieman DC (1997) J Appl Physiol 82, 1385-1394

3. Hoffman-Goetz L \& Pedersen BK (1994) Immunol Today 15, 382-387.

4. Shephard RJ (1997) Physical Activity, Training and the Immune Response. Carmel, IN: Cooper Publishing Group.

5. Nieman DC \& Pedersen BK (1999) Sports Med 27, 73-80. 